\title{
A Researchon Tribological Behaviourof Pongamia Biodiesel Blended Lubricant with Cardanol Biodiesel Blended Lubricant at Different Loads
}

\author{
S. Suresh, R.S.Mohan Kumar, Arun G P, Siva M
}

\begin{abstract}
In this world demand for bio lubricants which are easily decomposing, non-toxic and non-polluting is increasing day by day. This paper describes and compares the friction and wear characteristics of Pongamia blended lubricant with Cardanol blended lubricant by using Pin on disc wear testing Tribometer. For the preparation of blended lubricants, cardanol and pongamia based biodiesel were blended with base lubricant SAE20W40 in the ratios of 5,10 , and $20 \%$ on volume basis. The friction and wear characteristics of Cardanol and pongamia blended bio lubricants were carried out at the loads of $50 \mathrm{~N}, 100 \mathrm{~N}$ and $150 \mathrm{~N}$ with the sliding velocity of $2.5 \mathrm{~m} / \mathrm{s}$. By adding $5 \%$ and $10 \%$ pongamia biodiesel with base lubricant, less wear rate was observed. When this limit wear rate exceeds is also increasing gradually. While carrying out the wear test with Cardanol oil blended lubricant, least wear rate was observed during the addition of 5\% and 20\% Cardanol oil blended lubricant with base lubricant. The wear rate was increased while adding $10 \%$ of Cardanol oil blended lubricant with base lubricant. It has been concluded that CBL 5 and CBL 15 can act as an alternative lubricant at minimum and maximum load to increase mechanical efficiency at $2.5 \mathrm{~m} / \mathrm{s}$ sliding velocity and dependency on petroleum-based products was reduced with its contribution.
\end{abstract}

Keywords-Pongamia, Cardanol, Wear and Friction, Blending Ratio

\section{INTRODUCTION}

To reduce the wear and friction rate a lubricant is used in sliding parts. A lubricant is used to reduce friction in engine parts such as piston ring and cylinder liner. Since the world has met with major threat with non-renewable resources, so renewable resources play a vital role [2]. Petroleum based products has caused global issues such as pollution, so nonpetroleum-based products are used. Due to increase in population and a greater number of industries large quantities of lubricant is required [6]. To meet this requirement vegetable/plant seed oils and major renewable sources of lubricants are used. When compared to mineral oil, vegetable oil has good flash point and better viscosity index. Vegetable oil is biodegradable and non-polluting compared to mineral oil. Vegetable oil also has limitations

Revised Manuscript Received on August 19, 2019.

S. Suresh,Assistant Professor Department of Mechanical Engineering, Kumaraguru College of Technology, Coimbatore, Tamil Nadu, India. (suresh.s.mec@kct.ac.in)

R.S.Mohan Kumar,Assistant Professor Department of Mechanical Engineering, Kumaraguru College of Technology, Coimbatore, Tamil Nadu, India.

Arun G P, Student, Department of Automobile Engineering, Kumaraguru College of Technology, Coimbatore, Tamil Nadu, India.

Siva M, Student, Department of Automobile Engineering, Kumaraguru College of Technology, Coimbatore, Tamil Nadu, India. such as lower thermo-oxidative, poor cold flow properties and hydrolytic stability [6]. So, there is some need to change the plant's oil seed structure to meet the lubricant need. We have used Pongamia blended lubricant and Cardanol blended lubricant to study and compare the wear rate and frictional force characteristics at different sliding velocities and different loads [5]. Pongamia is extracted from the seeds of Milleteiapinnatatree; it is cultivated mostly in tropical and temperate Asia [1]. Cardanol is the main component of cashew nut shell liquid. It is a phenolic lipid of anacardic acid.

\section{EXPERIMENTAL PROCEDURE}

The pin on disc is used to conduct the wear rate and frictional force of the materials. The pin on disc consists of a horizontal rotting disc and a calibrated deadweight loaded pin [3].The experimental set up of pin disc is given below in the figure.

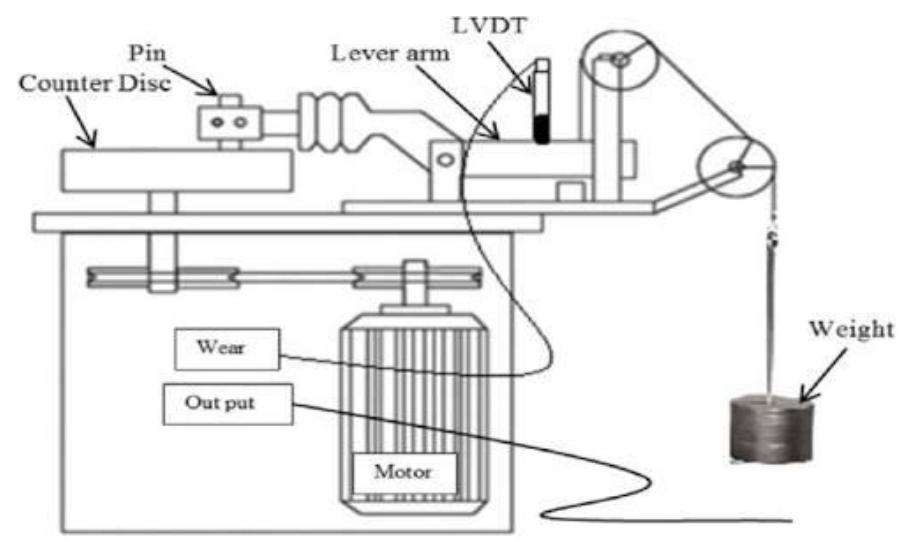

Fig.1. Schematic layout of Pin on disc wear testing Equipment

It also consists of a motor which rotates the disc. It mainly works under the LVDT sensor (Linear variable differential transformers). The Rotating disc undergoes wear due to pin and the pin makes contact with the disc by LVDT sensor[3,4]. The pin is carried on the lever arm as respectively by the weight given.

Published By:

Blue Eyes Intelligence Engineering

\& Sciences Publication 
Table 1. Details of Pin on Disc Apparatus

\begin{tabular}{|l|l|}
\hline Instrument type & Pin on Disc \\
\hline Disc Speed & 200 to $2000 \mathrm{rpm}$ \\
\hline Load range & $1 \mathrm{~N}$ to $2000 \mathrm{~N}$ \\
\hline Frictional force & 0 to $200 \mathrm{~N}$ \\
\hline Wear & $\pm 2 \mathrm{~mm}$ \\
\hline Sliding Speed & Min $0.5 \mathrm{~m} / \mathrm{s}$ to $\mathrm{Max} 10 \mathrm{~m} / \mathrm{s}$ \\
\hline
\end{tabular}

With various loads such as $50 \mathrm{~N}, 100 \mathrm{~N}$ and $150 \mathrm{~N}$ the experimental setup is carried out using pongamia oil based biodiesel mixed with the lubricant (SAE20W40) in ratios such as 5\%PBL, 10\%PBL and 20\%PBL [4]. With the above mentioned loads the experimental setup is also carried out using cardanol based biodiesel mixed with the same lubricant with same proportions as above such as $5 \% \mathrm{CBL}$, $10 \% \mathrm{CBL}$ and $20 \% \mathrm{CBL}$. The mixing is done with a magnetic stirrer. To conduct an experiment first the disc is rubbed with sand paper and the experiment was carried out. With various loads and various proportions the experiment was conducted and readings were obtained. For these readings graphs were plotted for coefficient of friction, wear rate and Load correspondingly.

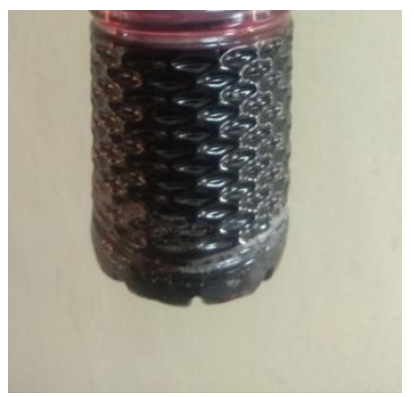

Fig 2. Oil sample of cardanol oil blended with base lubricant

The figure represents the samples of Cardanol based biodiesel and Pongamia based Biodiesel in the ratios of above mentioned proportions.

\section{RESULTS AND DISCUSSION}

\section{Effect of Load on wear rate}

The effect of load on wear rate is shown in the figure 3.The wear rate is increased for variant loads, however the PBL 5 and PBL10 shows minimum wear rate when compared to PBL15.And from the figure 4 ,the CBL 5 and CBL 15 shows minimum wear rate when compared to CBL10.

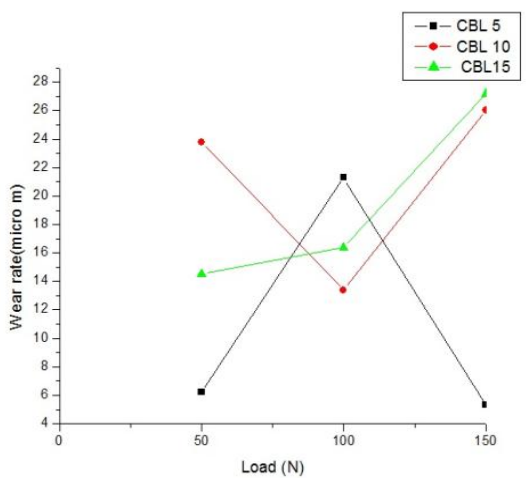

Fig.3 Load vs Wear rate for CBL

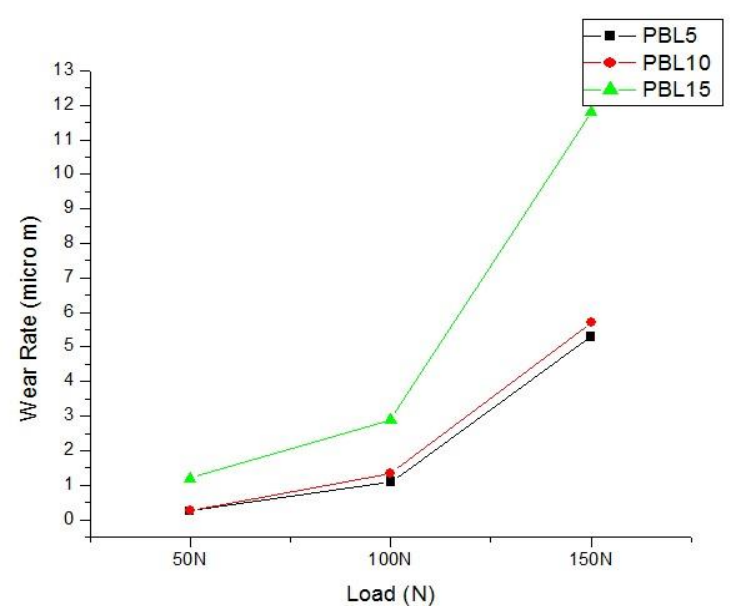

Fig.4 Load vs Wear rate for PBL

\section{A. Effect of Load on coefficient of friction}

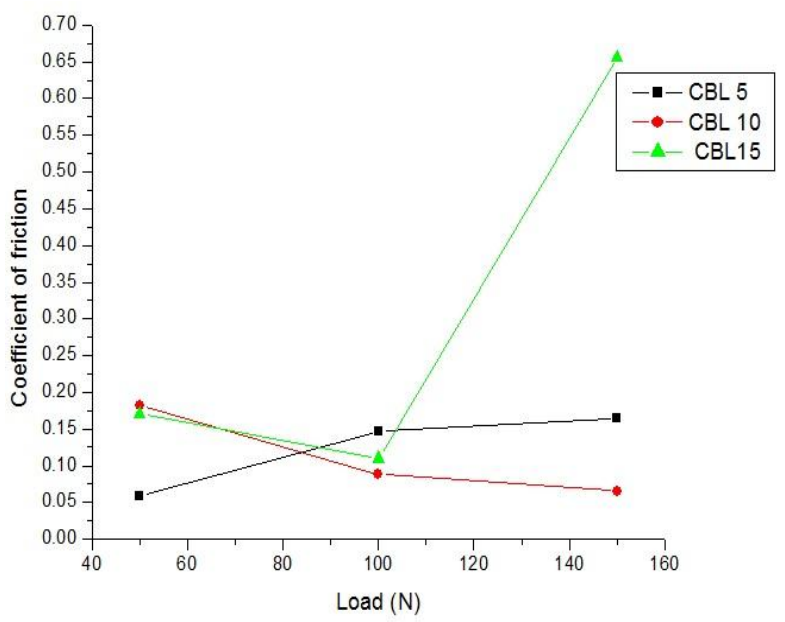

Fig.5 Load vs Coefficient of friction for CBL

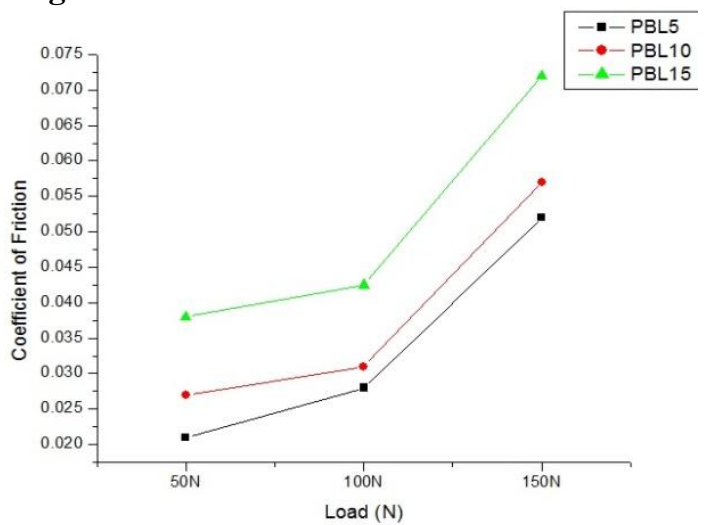

Fig.6 Load vs Coefficient of friction for PBL

The effect of load on coefficient of friction is shown in the figure 5 and 6 . Figure shows the coefficient of friction is minimum for PBL 5 and PBL10 when compared to PBL15. Simultaneously CBL5 and CBL15 show minimum coefficient of friction while compared to CBL10. 
IV.

CONCLUSIONS

Based on the above work it is concluded that,

1. Less wear rate was observed while adding $5 \%$ and $15 \%$ of Cardanol oil with Base lubricant oil.

2. While adding $5 \%$ and $10 \%$ of Pongamia oil with the Base lubricant less wear rate was observed.

\section{ACKNOWLEDGMENT}

Authors thank the management of Kumaraguru College of Technology, Coimbatore - India for providing facilities to carry out the research work.

\section{REFERENCES}

1. Alves, S. M., Barros, B. S., Trajano, M. F., Ribeiro, K. S. B., and Moura, E. 2013. Tribologicalbehavior of vegetable oilbased lubricants with nanoparticles of oxides in boundary lubricationconditions. Tribol. Int. 65:28-36.

2. Gui, M. M., Lee, K. T., and Bhatia, S. 2008. Feasibility of edible oil vs. non-edible oil vs. waste edible oil as biodiesel feedstock. Energy 33:1646-1653.

3. Maleque, M. A., Masjuki, H. H., Haseeb, A. S. M. A. 2000. Effect of mechanical factors on tribological properties of palm oil methyl ester blended lubricant. Wear 239:117-125.

4. Agalya, A., B. Nagaraj, and K. Rajasekaran. "Concentration control of continuous stirred tank reactor using particle swarm optimization algorithm." Trans EngSci 1, no. 4 (2013): 57-63.

5. He, Z., Lu, J., Zeng, X., Shao, H., Ren, T., and Liu, W. 2004. Study of the tribologicalbehaviors of $\mathrm{S}, \mathrm{P}$-containing triazine derivatives as additives in rapeseed oil. Wear 257:389-394.

6. S. Sivakumar, VenkatachalamRamasamy, NedunchezhianNatarajan, SivakumarPandianOptimization of non transesterifiedcardanol as biofuel based on its physical and chemical properties Journal of Chemical and Pharmaceutical Sciences 7:15-18 - January 2015.

7. Zengshe Liu, Jie Chen, Gerhard Knothe, XiaoanNie, and Jianchun Jiang Synthesis of EpoxidizedCardanol and Its Antioxidative Properties for Vegetable Oils and Biodiesel ACS Sustainable Chem. Eng., 2016, 4 (3), pp 901-906.

8. Shahabuddin, M., Masjuki, H. H., Kalam, M. A., Bhuiya, M. M. K., Mehat, H. 2013.Comparative tribological investigation of biolubricant formulated from a non-edible oil source (Jatropha oil). Ind Crops Prod. 47:323-330. Tullao, A. H. 2007. A new life for old plants. Chem. Eng. News Arch. 85:53-55 